7-1-2004

\title{
Predictors of paralysis in the rheumatoid cervical spine in patients undergoing total joint arthroplasty.
}

Jonathan N Grauer

Department of Orthopaedics, Yale University School of Medicine

Edwin M Tingstad

Inland Orthopaedics

Nahshon Rand

Israel Spine Center

Michael J Christie

Southern Joint Replacement Institute

Alan Hilibrand

Rothman Institute Thomas Jefferson University

Follow this and additional works at: https://jdc.jefferson.edu/rothman_institute

Part of the Orthopedics Commons

Let us know how access to this document benefits you

\section{Recommended Citation}

Grauer, Jonathan N; Tingstad, Edwin M; Rand, Nahshon; Christie, Michael J; and Hilibrand, Alan, "Predictors of paralysis in the rheumatoid cervical spine in patients undergoing total joint arthroplasty." (2004). Rothman Institute Faculty Papers. Paper 11.

https://jdc.jefferson.edu/rothman_institute/11

This Article is brought to you for free and open access by the Jefferson Digital Commons. The Jefferson Digital Commons is a service of Thomas Jefferson University's Center for Teaching and Learning (CTL). The Commons is a showcase for Jefferson books and journals, peer-reviewed scholarly publications, unique historical collections from the University archives, and teaching tools. The Jefferson Digital Commons allows researchers and interested readers anywhere in the world to learn about and keep up to date with Jefferson scholarship. This article has been accepted for inclusion in Rothman Institute Faculty Papers by an authorized administrator of the Jefferson Digital Commons. For more information, please contact: JeffersonDigitalCommons@jefferson.edu. 


\title{
Predictors of Paralysis in The Rheumatoid Cervical Spine in Patients Undergoing TOtAl Joint Arthroplasty
}

\author{
By Jonathan N. Grauer, MD, EdWin M. Tingstad, MD, NAHShOn Rand, MD, \\ Michael J. Christie, MD, AND ALAN S. HilibRAND, MD \\ Investigation performed at Vanderbilt University, Nashville, Tennessee
}

\begin{abstract}
Background: Rheumatoid arthritis is sometimes associated with radiographic evidence of instability of the cervical spine, most commonly an abnormal subluxation between vertebrae. When this instability compromises the space that is available for the spinal cord, it may be predictive of paralysis. However, the prevalence of radiographic signs of instability that are predictive of paralysis among patients with nonspinal orthopaedic manifestations of rheumatoid arthritis is unknown.
\end{abstract}

Methods: Radiographs of the cervical spine of patients with rheumatoid arthritis who had undergone total joint arthroplasty over a five-year period were retrospectively reviewed. The radiographs were evaluated for predictors of paralysis (a posterior atlantodental interval of $<14 \mathrm{~mm}$ or a subaxial space available for the cord measuring $<14 \mathrm{~mm}$ ) and were compared with traditional parameters of instability (an anterior atlantodental interval of $>3 \mathrm{~mm}$ or subaxial subluxation of $>3 \mathrm{~mm}$ ).

Results: Forty-nine of the sixty-five patients who were identified had flexion and extension lateral radiographs available for review. Only one of these patients had a posterior atlantodental interval of $<14 \mathrm{~mm}$, and only three had a space available for the cord that measured $<14 \mathrm{~mm}$ at one level or more. In comparison, twenty patients had radiographic evidence of instability on the basis of traditional parameters.

Conclusions: Although nearly one-half of the patients in the present study had radiographic evidence of cervical instability on the basis of traditional measurements, only four patients (8\%) had a radiographic finding that was predictive of paralysis. Thus, while radiographic evidence of cervical instability was not infrequent in this population of patients who underwent total joint arthroplasty for rheumatoid arthritis, radiographic predictors of paralysis were much less common.

$\mathrm{R}$ heumatoid arthritis is a chronic inflammatory disorder that is characterized by polyarticular involvement of the peripheral joints and the cervical spine. It has been estimated that $17 \%$ to $86 \%$ of patients with rheumatoid arthritis have evidence of involvement of the cervical spine'. Such cervical spine involvement occurs relatively early in the course of rheumatoid arthritis, and most patients demonstrate radiographic changes in the cervical spine within the first few years after diagnosis ${ }^{2,3}$. Three characteristic patterns of instability have been described: atlantoaxial subluxation, cranial settling (also known as basilar invagination), and subaxial subluxation ${ }^{3-7}$. Although previous authors have reported that an abnormal anterior atlantodental interval is indicative of upper cervical instability ${ }^{8}$, more recent studies have suggested that this finding correlates poorly with the risk of neu- rologic deterioration ${ }^{9,10}$. Boden et al. found that a posterior atlantodental interval of $<14 \mathrm{~mm}$ and a subaxial space available for the cord of $<14 \mathrm{~mm}$ were more reliable predictors of paralysis?.

Several studies have demonstrated a correlation between the development of cervical instability and destruction of the peripheral joints ${ }^{7,11}$. As a result, cervical spine radiographs are routinely made before any orthopaedic operative procedure requiring endotracheal intubation in patients with rheumatoid disease. This practice was supported by Collins et al., who found that sixty-nine $(59 \%)$ of 116 patients with rheumatoid arthritis who were undergoing elective hip or knee arthroplasty had either an anterior atlantodental interval of $>3 \mathrm{~mm}$ or a subaxial subluxation of $>3 \mathrm{~mm}^{12}$. However, Boden et al. showed that an abnormal anterior atlantodental interval and/or subax- 
The JOURnal of BOnE \& JOINT Surgery · JBJS.ORG VOLUme 86-A · Number 7 · JuLY 2004
Predictors of Paralysis in the Rheumatoid Cervical Spine in Patients Undergoing Total Joint Arthroplasty

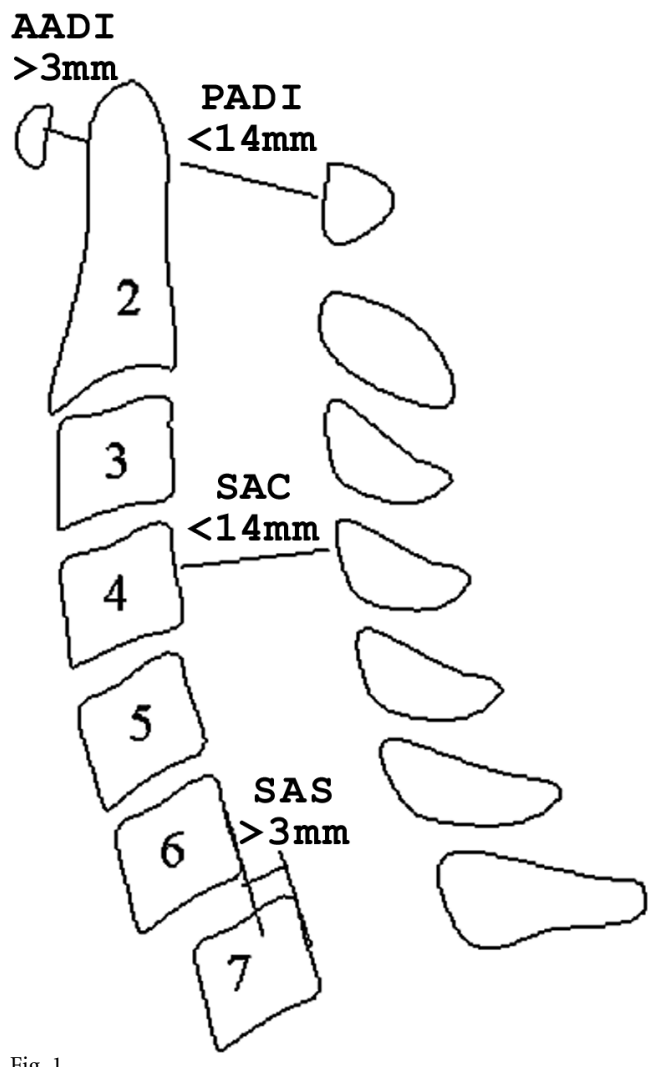

Fig. 1

Illustration showing the cervical measurements that were indicative of instability. AADI = anterior atlantodental interval, PADI = posterior atlantodental interval, $\mathrm{SAC}=$ space available for the cord, and SAS = subaxial subluxation. ial subluxation correlated poorly with neurologic risk ${ }^{9}$.

The purpose of the present study was to determine the prevalence of the predictors of paralysis, as defined by Boden et al. ${ }^{9}$, among patients with rheumatoid arthritis who were undergoing total joint arthroplasty. For comparison purposes, we also recorded the prevalence of an abnormal anterior atlantodental interval and subaxial subluxation in the same group of patients and determined the reliability of repeated measurements of these parameters by three orthopaedic surgeons.

\section{Materials and Methods}

The Division of Human Subjects Protection of the Institu-

Itional Review Board reviewed and approved the study protocol. The hospital charts of all patients who had been managed with a total hip or total knee arthroplasty by the senior surgeon (M.J.C.) at a single institution between 1991 and 1995 were reviewed. All patients who had been diagnosed with rheumatoid arthritis on the basis of established criteria ${ }^{13}$ were identified. Flexion and extension lateral radiographs of the cervical spine that had been made at the time of the total joint arthroplasty were collected for each of these patients.

A total of sixty-five patients who met the inclusion criteria were identified and, of these, forty-nine had appropriate radiographs available for review. The average age of the patients at the time of the joint arthroplasty was sixty-two years (range, thirty-one to eighty-eight years), and the female-tomale ratio was 4.4:1. Flexion and extension lateral radiographs of the cervical spine that had been made at the time of the arthroplasty were available for all forty-nine of these patients. For the sixteen patients who did not have adequate radiographs available for review, hospital and outpatient records were searched in order to confirm that none of these patients had undergone cervical spine surgery; all sixteen of these patients were excluded from the study.

Each set of radiographs was then independently evalu-

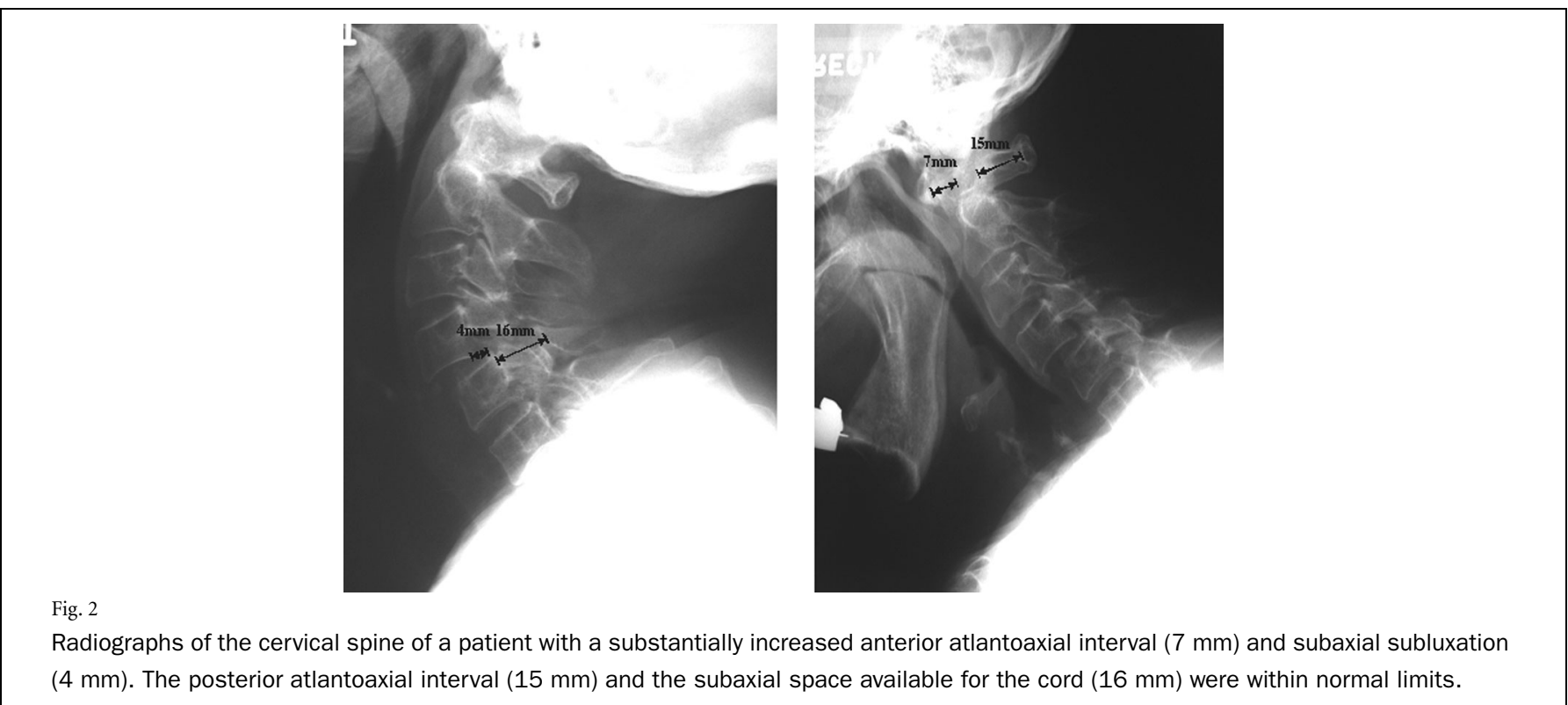




\begin{tabular}{|c|c|c|c|c|}
\hline Level & $\begin{array}{l}\text { Anterior Atlantodental } \\
\text { Interval }(\mathrm{mm})\end{array}$ & $\begin{array}{l}\text { Posterior Atlantodental } \\
\text { Interval }(\mathrm{mm})\end{array}$ & $\begin{array}{c}\text { Subaxial } \\
\text { Subluxation }(\mathrm{mm})\end{array}$ & $\begin{array}{l}\text { Space Available } \\
\text { for the Cord }(\mathrm{mm})\end{array}$ \\
\hline C1-C2 & $2.7 \pm 0.1$ & $20.9 \pm 0.2$ & & \\
\hline C2-C3 & & & $0.5 \pm 0.1$ & $18.0 \pm 0.1$ \\
\hline C3-C4 & & & $1.0 \pm 0.1$ & $17.5 \pm 0.2$ \\
\hline C4-C5 & & & $0.7 \pm 0.1$ & $17.2 \pm 0.2$ \\
\hline C5-C6 & & & $0.5 \pm 0.1$ & $17.2 \pm 0.1$ \\
\hline C6-C7 & & & $0.1 \pm 0.0$ & $17.3 \pm 0.1$ \\
\hline
\end{tabular}

ated by three reviewers, all of whom were unaware of the clinical and neurologic status of the patients. Four parameters were measured: the posterior atlantodental interval, the subaxial space available for the cord, the anterior atlantodental interval, and subaxial subluxation (Figs. 1 and 2). The greatest measurement on either flexion or extension lateral radiographs was recorded. Instability was defined as a posterior atlantodental interval of $<14 \mathrm{~mm}$, a subaxial space available for the cord of $<14 \mathrm{~mm}$ at one level or more, an anterior atlantodental interval of $>3 \mathrm{~mm}$, or subaxial subluxation of $>3 \mathrm{~mm}$ at one level or more. All radiographs were read twice by each reviewer, and the values were averaged. The readings by the three reviewers were then averaged, and the standard error of the measurements was obtained.

\section{Results}

The average measurements for all forty-nine patients are 1 shown in Table I. The spinal segments that demonstrated instability, as defined in Figure 1, are presented in Table II.

Only one patient had an abnormal posterior atlantodental interval, and three patients had an abnormal subaxial space available for the cord (Tables II and III). No patient had $<14 \mathrm{~mm}$ of subaxial space available for the cord at more than one level. Thus, four $(8 \%)$ of the forty-nine patients had pre- dictors of paralysis according to the criteria of a posterior atlantodental interval of $<14 \mathrm{~mm}$ and/or a space available for the cord of $<14 \mathrm{~mm}$.

Fifteen patients $(31 \%)$ had an abnormal anterior atlantodental interval, and seven patients (14\%) had abnormal subaxial subluxation (Table III). Subaxial subluxation was present at one level in three patients, at two levels in three patients, and at three levels in one patient. Of the three patients with an abnormal space available for the cord, only one had subaxial subluxation of $>3 \mathrm{~mm}$. In total, twenty $(41 \%)$ of the forty-nine patients had one measure of instability or more.

Three of the forty-nine patients had previously undergone atlantoaxial arthrodesis. One of these patients had development of a pseudarthrosis at the C1-C2 level and had a posterior atlantodental interval of $12 \mathrm{~mm}$ in flexion and an anterior atlantodental interval of $5 \mathrm{~mm}$; the subaxial measurements for this patient were unremarkable. The two other patients went on to have a solid fusion and had normal anterior atlantodental and posterior atlantodental intervals. However, one of these patients had a space available for the cord of 13 $\mathrm{mm}$ at $\mathrm{C} 3-\mathrm{C} 4$ and subaxial subluxation of $3 \mathrm{~mm}$ at $\mathrm{C} 2-\mathrm{C} 3$.

Of 1764 possible measurements, 1666 (94\%) were visualized sufficiently to be measured for the present study. The average interobserver difference was $1.3 \mathrm{~mm}$ for the anterior

TABLE II Number of Patients with Instability at Each Level*

\begin{tabular}{|c|c|c|c|c|}
\hline Level & $\begin{array}{l}\text { Anterior Atlantodental } \\
\text { Interval of }>3 \mathrm{~mm}\end{array}$ & $\begin{array}{l}\text { Posterior Atlantodental } \\
\text { Interval of }<14 \mathrm{~mm}\end{array}$ & $\begin{array}{l}\text { Subaxial Subluxation } \\
\text { of }>3 \mathrm{~mm}\end{array}$ & $\begin{array}{l}\text { Space Available for } \\
\text { the Cord of }<14 \mathrm{~mm}\end{array}$ \\
\hline C1-C2 & 15 (31\%) & $1(2 \%)$ & & \\
\hline C2-C3 & & & $3(6 \%)$ & $1(2 \%)$ \\
\hline C3-C4 & & & $3(6 \%)$ & $1(2 \%)$ \\
\hline C4-C5 & & & $4(8 \%)$ & $0(0 \%)$ \\
\hline C5-C6 & & & 2 (4\%) & $0(0 \%)$ \\
\hline $\mathrm{C} 6-\mathrm{C} 7$ & & & $0(0 \%)$ & $1(2 \%)$ \\
\hline
\end{tabular}

*The values are given as the number of patients, with the percentage in parentheses. All percentages are based on a denominator of fortynine patients. 
The JOURnAL of BOnE \& JOINT SURGERY · JBJS.ORG VOlume 86-A · Number 7 • July 2004
Predictors of Paralysis in the Rheumatoid Cervical Spine in Patients Undergoing Total Joint Arthroplasty
TABLE III Number of Patients with Each Type of Instability, Regardless of Level*

\begin{tabular}{|lc|}
\hline \multicolumn{1}{|c}{ Type of Instability } & $\begin{array}{c}\text { Number of } \\
\text { Patients }\end{array}$ \\
\hline Anterior atlantodental interval of $>3 \mathrm{~mm}$ & $15(31 \%)$ \\
Posterior atlantodental interval of $<14 \mathrm{~mm}$ & $1(2 \%)$ \\
Subaxial subluxation of $>3 \mathrm{~mm}$ & $7(14 \%)$ \\
Space available for the cord of $<14 \mathrm{~mm}$ & $3(6 \%)$ \\
\hline
\end{tabular}

*The values are given as the number of patients, with the percentage in parentheses. All percentages are based on a denominator of forty-nine patients. The number of patients with subaxial subluxation is less than the sum total of the levels of instability in Table II because some patients had instability at more than one level, as described in the text.

atlantodental interval, $2.0 \mathrm{~mm}$ for the posterior atlantodental interval, $0.6 \mathrm{~mm}$ for subaxial subluxation, and $1.5 \mathrm{~mm}$ for the space available for the cord.

\section{Discussion}

M ost orthopaedic surgeons make flexion and extension 1 lateral radiographs for all patients with rheumatoid arthritis who are scheduled to undergo total joint arthroplasty. This practice is supported by the presumed prevalence of cervical instability in these patients ${ }^{3-7}$ as well as by the findings of Collins et al., who reported an abnormal anterior atlantodental interval and subaxial subluxation in fifty-five (49\%) and twenty-four $(21 \%)$ of 113 patients, respectively, who were undergoing total joint arthroplasty ${ }^{12}$.

Nevertheless, Boden et al. found that the posterior atlantodental interval and the space available for the cord were much better predictors of neurologic compromise than were the anterior atlantodental interval and subaxial subluxation'. Those investigators reviewed seventy-three patients, all of whom had been specifically referred for the treatment of rheumatoid arthritis of the cervical spine. Consequently, many of the patients in their study had radiographic parameters that were predictive of paralysis. In comparison, we assessed patients with severe joint destruction of the hips and/or knees who were scheduled to undergo total joint arthroplasty. Therefore, we believe that the patients in the present study are more representative of those who are seen by orthopaedic surgeons in clinical practice.

To our knowledge, the prevalence of the predictors of paralysis (as described by Boden et al.) has never been reported for a population of patients with rheumatoid arthritis who were scheduled to undergo total joint arthroplasty. In the present study, all patients had documented rheumatoid arthritis with notable hip and/or knee involvement requiring total joint arthroplasty. Radiographic landmarks were clearly visualized for 1666 (94\%) of 1764 of the measurements, and the average interobserver variation was only $1.4 \mathrm{~mm}$. Only four $(8 \%)$ of the forty-nine patients had an abnormal posterior atlantodental interval or space available for the cord that was predictive of paralysis. In comparison, twenty $(41 \%)$ of these same forty-nine patients had radiographic evidence of instability (an abnormal anterior atlantodental interval or subaxial subluxation). Furthermore, of the four patients who had a predictor of paralysis, two had known upper cervical instability and had already undergone atlantoaxial arthrodesis. Unfortunately, we could not ascertain from the available medical records whether the other two patients demonstrated symptoms of cervical spondylitis. However, this implies that, at most, only two patients in the present study may have had predictors of paralysis that were not evident clinically.

The present study suggests that the prevalence of cervical instability that is predictive of paralysis in patients with rheumatoid arthritis who require total joint arthroplasty may be much lower than previously reported ${ }^{12}$. This observation is consistent with that of Christensson et al., who found only seventy-four patients with rheumatoid arthritis in the Swedish population (of approximately eight million people) who required cervical stabilization procedures in $1993^{14}$.

The applicability of the current study is limited by the relatively small number of patients. This was largely due to our strict inclusion criteria that defined patients with rheumatoid arthritis as those in whom the disease had been documented and who had peripheral manifestations that were sufficient to require total joint arthroplasty. In addition, the study was retrospective and radiographic in nature. As such, neurologic findings were not consistently documented in the medical records and thus were not directly considered. Correlation between predictors of paralysis and neurologic dysfunction, well described by Boden et al. ${ }^{9}$, was not repeated in the present study.

Jonathan N. Grauer, MD

Department of Orthopaedics, Yale University School of Medicine, P.O. Box 208071, New Haven, CT 06520-8071

Edwin M. Tingstad, MD

Inland Orthopaedics, 825 Bishop Boulevard, Suite 120, Pullman, WA 99163

Nahshon Rand, MD

Israel Spine Center, Assuta Hospital, 62 Jabotinsky Street, Tel-Aviv 62748, Israel

Michael J. Christie, MD

Southern Joint Replacement Institute, 2021 Church Street, Suite 104, Nashville, TN 37203

Alan S. Hilibrand, MD

Jefferson Medical College/Rothman Institute, 925 Chestnut Street, 5th Floor, Philadelphia, PA 19107

The authors did not receive grants or outside funding in support of their research or preparation of this manuscript. They did not receive payments or other benefits or a commitment or agreement to provide such benefits from a commercial entity. No commercial entity paid or directed, or agreed to pay or direct, any benefits to any research fund, foundation, educational institution, or other charitable or nonprofit organization with which the authors are affiliated or associated. 
The JOURnal of BOnE \& JOINT SURGERY · JBJS.ORG VOLUME 86-A · NUMBER 7 · JULY 2004
Predictors of Paralysis in the Rheumatoid Cervical Spine

in Patients Undergoing Total Joint Arthroplasty

\section{References}

1. Rawlins BA, Girardi FP, Boachie-Adjei O. Rheumatoid arthritis of the cervical spine. Rheum Dis Clin North Am. 1998;24:55-65.

2. Paimela L, Laasonen L, Kankaanpaa E, Leirisalo-Repo M. Progression of cervical spine changes in patients with early rheumatoid arthritis. J Rheumatol. 1997;24:1280-4.

3. Winfield J, Cooke D, Brook AS, Corbett M. A prospective study of the radiological changes in the cervical spine in early rheumatoid disease. Ann Rheum Dis. 1981;40:109-14.

4. Dreyer SJ, Boden SD. Natural history of rheumatoid arthritis of the cervical spine. Clin Orthop. 1999;366:98-106.

5. Halla JT, Hardin JG, Vitek J, Alarcon GS. Involvement of the cervical spine in rheumatoid arthritis. Arthritis Rheum. 1989;32:652-9.

6. Neva MH, Kaarela K, Kauppi M. Prevalence of radiological changes in the cervical spine-a cross sectional study after 20 years from presentation of rheumatoid arthritis. J Rheumatol. 2000;27:90-3.

7. Oda T, Fujiwara K, Yonenobu K, Azuma B, Ochi T. Natural course of cervical spine lesions in rheumatoid arthritis. Spine. 1995;20:1128-35.

8. Fielding JW, Cochran GB, Lawsing JF 3rd, Hohl M. Tears of the transverse ligament of the atlas. A clinical and biomechanical study. J Bone Joint Surg Am. 1974;56:1683-91.
9. Boden SD, Dodge LD, BohIman HH, Rechtine GR. Rheumatoid arthritis of the cervical spine. A long-term analysis with predictors of paralysis and recovery. J Bone Joint Surg Am. 1993;75:1282-97.

10. Castro S, Verstraete K, Mielants H, Vanderstraeten G, de Reuck J, Veys EM. Cervical spine involvement in rheumatoid arthritis: a clinical, neurological and radiological evaluation. Clin Exp Rheumatol. 1994;12:369-74.

11. Winfield J, Young A, Williams $\mathbf{P}$, Corbett $\mathbf{M}$. Prospective study of the radiolog ical changes in hands, feet, and cervical spine in adult rheumatoid disease. Ann Rheum Dis. 1983;42:613-8.

12. Collins DN, Barnes CL, FitzRandolph RL. Cervical spine instability in rheumatoid patients having total hip or knee arthroplasty. Clin Orthop. 1991; 272:127-35.

13. Arnett FC, Edworthy SM, Bloch DA, McShane DJ, Fries JF, Cooper NS, Healey LA, Kaplan SR, Liang MH, Luthra HS, Medsger TA Jr, Mitchell DM, Neustadt DH, Pinals RS, Schaller JG, Sharp JT, Wilder RL, Hunder GG. The American Rheumatism Association 1987 revised criteria for the classification of rheumatoid arthritis. Arthritis Rheum. 1988;31: 315-24.

14. Christensson D, Saveland H, Rydholm U. Cervical spine surgery in rheumatoid arthritis. A Swedish nation-wide registration of 83 patients. Scand J Rheumatol. 2000;29:314-9. 